\title{
Provisional Surgical Training Programs for Increasing Surgical Capacity in Rural Areas in Niger: Reply to Letter
}

\author{
Rachid Sani $\cdot$ Babadi Nameoua $\cdot$ Abou Yahaya $\cdot$ \\ Ide Hassane • Roua Adamou • Renee Y. Hsia • \\ Patrick Joekman · Amadou Sako • Abarchi Habibou
}

Published online: 16 July 2010

(C) The Author(s) 2010. This article is published with open access at Springerlink.com

We appreciate the response to our article from Dr. Emmanual Monjok and heartily concur that especially in limitedresource settings, it is neither practical nor helpful to the communities that seek care to follow models that have been developed in other contexts with a different set of available resources. We have devised this program in Niger with the idea that this is a provisional solution until there are enough formally trained surgeons to live in rural areas. We have been able to implement this program with the help of financial partners collaborating with our Ministry of Health, and wholeheartedly agree that a comprehensive approach—one that involves a department of higher education and healthis required for addressing the problem of coverage of essential surgical care.

Open Access This article is distributed under the terms of the Creative Commons Attribution Noncommercial License which permits any noncommercial use, distribution, and reproduction in any medium, provided the original author(s) and source are credited.

R. Sani · P. Joekman · A. Sako · A. Habibou

Department of Surgery, University of Niamey, Niamey, Niger

B. Nameoua

Regional Hospital of Dosso, Dosso, Niger

A. Yahaya · I. Hassane · R. Adamou

District Hospital, Dosso Region, Dosso, Niger

R. Y. Hsia ( $\square)$

Department of Emergency Medicine, University of California,

San Francisco, San Francisco, CA, USA

e-mail: rhsia@post.harvard.edu 